\title{
Evaluating the attitudes of individuals with a history of cancer towards exercise using the transtheoretical model
}

\section{Kanser öyküsü olan bireylerin egzersize yönelik tutumlarının transteoretik model ile değerlendirilmesi}

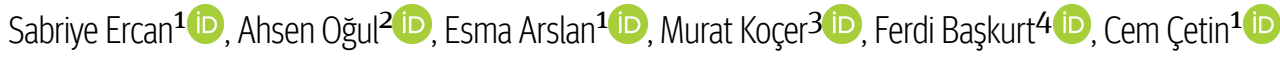 \\ ${ }^{1}$ Sports Medicine Department, Faculty of Medicine, Süleyman Demirel University, Isparta, Turkey \\ ${ }^{2}$ Sports Medicine Section, Gazi Yaşargil Training and Research Hospital, University of Health Sciences, Diyarbakir, Turkey \\ ${ }^{3}$ Department of Medical Oncology, Antalya Training and Research Hospital, University of Health Sciences, Antalya, Turkey \\ ${ }^{4}$ Department of Physiotherapy and Rehabilitation, Faculty of Health Sciences, Süleyman Demirel University, Isparta, Turkey
}

\section{ABSTRACT}

Objective: The purpose of this study was to assess the attitudes and demands about exercise of individuals with a medical history of cancer.

Materials and Methods: Regardless of the type of cancer, individuals with a history of cancer were included in the study. The sociodemographic characteristics of the participants, smoking, comorbid diseases, their knowledge of cancer, and about exercise habits and demands were questioned with a questionnaire prepared by the researchers.

Results: A total of 131 participants (61.1\% female, 38.9\% male; average age $51.8 \pm 11.3$ years) were included in the study. Average time elapsed since their diagnosis of cancer was $46.0 \pm 48.7$ months. About $26.7 \%$ of the participants reported that they had been doing regular physical activity in the past. Physical activity level was determined as $796.9 \pm 944.5 \mathrm{MET} /$ week. According to the stage of exercise behaviour change questionnaire, it was determined that the individuals participating in the study were at precontemplation (29.0\%), contemplation (9.9\%), preparation (17.6\%), action (19.1\%), and maintenance (24.4\%) stages. Most participants (67.9\%) wanted to get information about physical activity/exercise. Participants stated that they would request physicians (46.7\%), physiotherapists (22.2\%), and physicians and physiotherapists jointly (11.1\%) as a source of information. They most frequently requested to receive information in a face-to-face environment. The most common exercise type was walking (43.5\%). It was found that $32.8 \%$ of the participants thought they follow the suggested and explained/shown exercise program, the rate being higher in females. The rate of those who stated that they wanted to follow their exercise program with an observer was $68.3 \%$.

Conclusion: Assessing the conditions that prevent cancer patients from exercising, intervening in modifiable factors, and making exercise a part of the treatment process by considering their demands for physical activity may contribute to the health of patients.

Keywords: Cancer, exercise, physical activity

Öz

Amaç: Bu çalışmanın amacı; özgeçmişinde kanser öyküsü olan bireylerin egzersize yönelik tutumlarını ve taleplerini incelemektir.

Gereç ve Yöntem: Araştırmaya kanserin tipi ayırt edilmeksizin özgeçmișinde kanser öyküsü olan bireyler dahil edildi. Araștırmacılarca hazırlanan anket formu ile katıımcıların sosyodemografik özellikleri, sigara kullanımı, komorbid hastalık varlığı, kanser tanısına yönelik bilgi düzeyleri, egzersiz alışkanlığına ve taleplerine yönelik bilgi düzeyleri sorgulandı.

Bulgular: Araştırmaya 131 kişi (\%61.1 kadın, \%38.9 erkek; yaş ortalaması $51.8 \pm 11.3$ yıl) dahil edildi. Katıımcılara kanser tanısı konulmasının üzerinden geçen süre ortalama $46.0 \pm 48.7$ ay idi. Katılımcıların \%26.7'sı geçmişte düzenli fiziksel aktivitede bulunduğunu bildirmişti. Fiziksel aktivite düzeyi $796.9 \pm 944.5$ MET/hafta olarak belirlendi. Egzersiz değişim basamağı anketine göre araştırmaya katılan bireylerin \%29.0'unun eğilim öncesi, \%9.9'unun eğilim, \%17.6'sının hazılık, \%19.1'inin hareket ve \%24.4'ünün devamlılık basamağında oldukları saptandı. Katıtımcıların \%67.9'u fiziksel aktivite/egzersiz ile ilgili bilgi almak istedi. Bilgi kaynağı olarak \%46.7'si hekim, \%22.2'si fizyoterapist ve \%11.1'i hekim ile fizyoterapist birlikteliğini talep edeceklerini bildirdi. Bilgiyi en sık yüz yüze ortamda almak istediler. Egzersiz tipi olarak en sık yürüyüș (\%43.5) tercih edildi. Katıtımcıların \%32.8'i kendisine önerilen ve anlatılan/gösterilen egzersiz programını yapabileceğini belirtti; kadınların bu yöndeki beyanı erkeklerden daha yüksek oldu. Egzersiz programını gözetimli olarak sürdürmek istediğini bildirenlerin oranı \%68.3 olarak saptandı.

Sonuç: Kanser hastalarıın egzersiz yapmalarına engel olan durumların gözden geçirilerek değiştirilebilir faktörlere müdahalelerde bulunulması ve fiziksel aktiviteye yönelik taleplerinin dikkate alınarak egzersizin tedavi sürecinin bir parçası haline getirilmesi hastaların sağlığına katkıda bulunabilecektir.

Anahtar Sözcükler: Kanser, egzersiz, fiziksel aktivite 


\section{GiRiş}

Kanser hem maddi hem de manevi açıdan yükü fazla olan kronik bir hastalıktır. Dünya geneline bakıldığında bulaşıcı olmayan hastalık ölümleri arasında ikinci sırada yer almaktadır (1). Günümüzde kanser tarama programları ile erken tanının yanı sıra, tedavideki gelişmeler sayesinde de sağ kalım arttırılabilmektedir. Bununla birlikte; birçok kanser hastası, hastalık ve/veya tedavi kaynaklı yorgunluk, uyku bozukluğu, kronik ağrı, kas gücü ve dayanılklılığın azalması, fiziksel işlev kaybı, bilişsel işlevlerde bozulma, depresyon ve anksiyete gibi yaşam kalitelerini olumsuz etkileyen sorunlar yaşamaktadır (2-4). Yaşadıkları fiziksel ve psikososyal sorunları yönetmeye ve yaşam kalitesini iyileştirmeye yardımcı olmak için kanserli hastalara tedavinin bir parçası olarak egzersiz önerilmektedir (5). Egzersizin yararları arasında sağlığın ve fiziksel uygunluğun geliştirilmesi, işlevselliğin ve yaşam kalitesinin arttırılması, yorgunluğun ve depresyonun azaltılması yer almaktadır $(6,7)$.

Padilha ve ark.'nın 14 çalışmayı içeren meta-analizinde; neoadjuvan veya adjuvan tedavi alan kanser hastalarında direnç egzersizinin alt ekstremite kas kuvveti, yağsız vücut kütlesi ve vücut yağ1 üzerindeki etkileri incelenmiş; kemoterapi gören hastalarda kuvvet egzersizlerinin alt ekstremite kas gücünü ve işlevini iyileştirmenin yanı sıra yağsız vücut kütlesinin kaybını önlemede etkili olduğu bildirilmiştir (8). çeşitli çalışmalar yüksek fiziksel aktivite düzeylerinin kansere bağlı mortalite ve morbiditede azalma ile ilişkili olduğunu göstermektedir $(9,10)$. Literatürde egzersizin olumlu etkilerine dair kanıtlar bulunmasına rağmen, özgeçmişinde kanser öyküsü bulunan hastaların çoğunun haftada 150 dakikalık orta-şiddetli aerobik fiziksel aktivite ve haftada 2-3 gün kuvvet antrenmanı önerilerini karşılayamadığı belirtilmiştir (11). Kanser tanılı hastalara fiziksel aktiviteyi arttırmak için genel önerilerde bulunulurken ve egzersiz reçetesi düzenlenirken, egzersizin olumlu etkilerinden güvenli bir şekilde yararlanabilmek için birçok faktörün dikkate alınması gerekmektedir. Ayrıca, fonksiyonel bozukluk ve engellilik yaşayan bireyler için spesifik bir terapötik egzersiz yaklaşımı önerilmektedir $(12,13)$.

Onkolojik tedavi sürecinde bireyin sağlık durumu, klinik geçmişi ve fonksiyonel yetenekleri egzersiz programının belirlenmesi ile ilgili zorluk oluşturabilmekte; egzersiz reçetesi kanser tedavisi planlamasında göz ardı edilebilmektedir (14-16). Egzersize uyumu arttırarak en üst düzeyde yarar sağlayabilmek için, hedef grubun özelliklerini değerlendirmek önemlidir. Ayrıca egzersizin yararlarını optimize etmek için belirlenen egzersiz türü, süresi, sıklığı ve yoğunluğunun hasta tarafından yeterince anlaşılması gerekir $(17,18)$. Kanserli bireylerin fiziksel aktiviteye katılımlarını etkileyen faktörlerin belirlenmesi ve egzersiz tercihlerinin gözden ge- çirilmesi ile elde edilen bilgiler ışığında, sağlık ekibinin destek ve eğitim sunmasının, hastaların bu sorunları aşmalarına yardımcı olabileceği düşünülmektedir (19).

Ülkemizde kanser hastalarının egzersiz davranışlarını inceleyen ve taleplerini değerlendiren çalışma bulunmamaktadır. Bu çalışmanın amacı; özgeçmişinde kanser öyküsü olan bireylerin egzersize yönelik tutumlarını ve taleplerini incelemektir.

\section{GEREÇ ve YÖNTEM}

Araştırma, 25.06.2019 tarihli ve 195 numaralı yerel etik kurul kararı ile onaylanmıştır. çalışmanın evrenini; kanserin tipi ayırt edilmeksizin özgeçmişinde kanser öyküsü olan 18 yaşından büyük bireyler oluşturdu. Bu bireyler, araştırmacılar tarafından literatür taraması sonucu oluşturulan anket formunu yüz yüze ortamda doldurdular. Uygulama sırasında iletişim sorunu yaşanan bireyler $(n=23, \% 15)$ çalışmadan çıkarıldı.

\section{Metodolojik detaylar}

çalışmada kullanılan anket formu araştırıcılar tarafından literatür taraması yapılarak oluşturulmuştur. $\mathrm{Bu}$ formda; cinsiyet, yaş, vücut kütle indeksi (VKİ), medeni durum, yerleşim yeri, eğitim durumu, sigara alışkanlığı, ek hastalık ve düzenli ilaç kullanım varlığı, kanser tanısına yönelik bilgiler, egzersiz alışkanlığına ve taleplerine yönelik sorular yer almıştır. Egzersiz alışkanlığını değerlendirmek için Uluslararası Fiziksel Aktivite Anketi (UFAA) kısa formu (20) ve Egzersiz Davranışı Değişim Basamakları Anketi (21) kullanılmıştır.

Uluslararası Fiziksel Aktivite Anketi (UFAA) Kısa Formu: Ankette, bireylerin son hafta aktiviteleri sorgulanmakta ve fiziksel aktivite düzeyi bu ankette verilen yanıtlarla MET$\mathrm{dk} /$ hafta olarak hesaplanmaktadır. Aktivite düzeyleri 600 MET-dk/haftaaltındaki puanlar sedanter-düşük fiziksel aktif birey, 600-3000 MET-dk/hafta aralığındaki puanlar aktif birey ve 3000 MET-dk/hafta üstündeki puanlar yüksek fiziksel aktif birey olarak üçe ayrılmaktadır (22).

Egzersiz Davranışı Değişim Basamakları Anketi: Bu anket, sağlık eğitimleri konusunda (alkol ve sigara bağımlılığı tedavisi vb.) etkili bulunan ve egzersiz davranışını değerlendirmek için uyarlaması yapılmış transteoretik modele göre geliştirilmiştir ve dört sorudan oluşmaktadır. Katılımcılar evet/hayır yanıtlarına göre beş ayrı egzersiz davranışı basamağından birinde yer alırlar. Bu basamaklar, eğilim öncesi (1. ve 2. soru: hayır), eğilim (1. soru: hayır, 2. soru: evet), hazırlık (1. soru: evet, 3. soru: hayır), hareket (1. ve 3. soru: evet, 4. soru: hayır) veya devamlılık (1., 3. ve 4. soru: evet) olarak tanımlanır (21). 


\section{İstatistiksel analiz}

Analizler için SPSS v23 paket programı kullanıldı. Verilerin normal dağılıma uygunluğu Shapiro Wilks testiyle incelendi. Veriler, tanımlayıcı istatistiksel yöntemler kullanılarak değerlendirildi. Cinsiyet alt grupları bağımsız gruplarda $t$ testi ve ki-kare testi ile; hastalı̆̆ın bulunduğu periyoda (yeni tanılılar, aktif tedavi döneminde olanlar, tedavi sonras1 takip döneminde bulunanlar) göre ayrılan alt gruplar Monte Carlo düzeltmeli Kruskal-Wallis $\mathrm{H}$ testi ve ki-kare testi ile karşılaştırıldı. İstatistiksel anlamlılık düzeyi $\mathrm{p}<0.05$ olarak kabul edildi. Veriler; $n, \%$ ve ortalama \pm standart sapma olarak sunuldu.

\section{BULGULAR}

Araştırmaya 80'i (\%61.1) kadın, 51'i (\%38.9) erkek toplam 131 birey alındı. Ortalama yaşları $51.8 \pm 11.3$ y1l, VKİ $26.4 \pm$ $5.4 \mathrm{~kg} / \mathrm{m}^{2}$ ve kanser tanısı sonrası geçen süreleri $46.0 \pm 48.7$ aydı. Cinsiyet dikkate alındığında VKİ dışındaki özelliklerde fark saptanmadı (Tablo 1).

\begin{tabular}{|c|c|c|c|}
\hline Parametre & $\operatorname{Kad} ı n(n=80)$ & $\operatorname{Erkek}(n=51)$ & $p$ \\
\hline Yaş (y1l) & $51.3 \pm 10.3$ & $52.6 \pm 12.8$ & 0.52 \\
\hline VKI $\left(\mathrm{kg} / \mathrm{m}^{2}\right)$ & $27.6 \pm 5.9$ & $24.4 \pm 3.8$ & $0.001^{*}$ \\
\hline Tanı süresi (ay) & $51.8 \pm 47.7$ & $37.1 \pm 49.4$ & 0.09 \\
\hline Medeni durum & & & 0.28 \\
\hline Evli & $72.5(58)$ & $82.4(42)$ & \\
\hline Bekar & $27.5(22)$ & $17.6(9)$ & \\
\hline Eğitim durumu & & & 0.23 \\
\hline ilköğretim & $72.5(58)$ & $54.9(28)$ & \\
\hline Lise & $15.0(12)$ & $23.5(12)$ & \\
\hline Yüksekokul/Üniversite & $11.3(9)$ & $19.6(10)$ & \\
\hline Yüksek Lisans/Doktora & $1.2(1)$ & $2.0(1)$ & \\
\hline Ikamet yeri & & & 0.50 \\
\hline Köy & $7.5(6)$ & $7.8(4)$ & \\
\hline İlçe & $32.5(26)$ & $37.3(19)$ & \\
\hline Il merkezi/Büyükşehir & $60.0(48)$ & $54.9(28)$ & \\
\hline
\end{tabular}

\section{Katılımcılanı kanser tanısına ve sağlık durumlanına yöne- lik bilgiler}

çalışmaya katılan hastaların \%44.3'ü $(\mathrm{n}=58)$ meme, \%9.2'si $(\mathrm{n}=12)$ mide, \%7.6's1 $(\mathrm{n}=10)$ kolon, \%6.1'i $(\mathrm{n}=8)$ akciğer, \%4.6's1 ( $\mathrm{n}=6)$ endometrium, \%4.6's1 $(\mathrm{n}=6)$ prostat, \%23.6's1 ise diğer (sırasıyla; tiroid, over, lenf sistemi, pankreas, rektum, beyin, RES, nöroendokrin sistem, testis, mesane, özofagus, serviks, yumuşak doku) kanser tanısı almışlardı. Olguların \%7.o'si $(\mathrm{n}=9)$ yeni tanılı, \%52.7'si $(\mathrm{n}=69)$ tedavi aşamasında olan, \%40.3'ü $(\mathrm{n}=53)$ ise tedavisini tamamlayıp düzenli takip döneminde bulunan bireylerden oluşmaktaydı.

Tüm katılımcıların \%67.9'unun (n=89) bilinen ek hastalığı ve \%99.2'sinin $(n=130)$ devamlı kullandığı ilacı yoktu. Yaşamı boyunca sigara kullanmayanların oranı \%62.6 $(n=82)$ olarak belirlendi. Sağlıkla ilgili incelenen özelliklerde cinsiyete göre fark saptanmadı (Tablo 2).

\begin{tabular}{|c|c|c|c|}
\hline $\begin{array}{c}\text { Parametre } \\
\text { Tanı anındaki kanser evresi }\end{array}$ & $\operatorname{Kad} \ln (n=80)$ & $\operatorname{Erkek}(n=51)$ & $\begin{array}{c}\mathbf{p} \\
0.15\end{array}$ \\
\hline Bilinmeyen & $25.0(20)$ & $35.3(18)$ & \\
\hline Evre 1 & $12.5(10)$ & $15.7(8)$ & \\
\hline Evre 2 & $40.0(32)$ & 21.6 (11) & \\
\hline Evre 3 & $16.3(13)$ & $13.7(7)$ & \\
\hline Evre 4 & $6.3(5)$ & $13.7(7)$ & \\
\hline Bilinen ek hastalık & & & 0.09 \\
\hline Hayır & $61.3(49)$ & $78.4(40)$ & \\
\hline Evet & $38.8(31)$ & 21.6 (11) & \\
\hline Devamlı kullanılan ilaç & & & 1.00 \\
\hline Hayır & $98.8(79)$ & $100(51)$ & \\
\hline Evet & $1.25(1)$ & $\mathrm{O}(0)$ & \\
\hline Sigara alışkanlığı & & & 0.07 \\
\hline Halen içen & $5.0(4)$ & $15.7(8)$ & \\
\hline Bırakan & $26.3(21)$ & $31.4(16)$ & \\
\hline Hiç içmeyen & $68.8(55)$ & $52.9(27)$ & \\
\hline
\end{tabular}

\section{Katılımcılann fiziksel aktiviteye yönelik tutumlan}

Geçmişte düzenli fiziksel aktiviteye/egzersize katıldığı bir dönem olduğunu bildirenlerin oranı \%26.7 (n=35)'dir. Erkeklerin katılım oranı kadınlara kıyasla (Erkek, $\mathrm{n}=19$, \%37.2; kadın, $\mathrm{n}=16, \% 20.0$ ) yüksekti ( $\mathrm{p}=0.03)$. Son hafta fiziksel aktivite düzeyinin değerlendirildiği UFAA sonucu $796.9 \pm 944.5 \mathrm{MET} / \mathrm{hafta}$ olarak belirlendi. Cinsiyete $(\mathrm{p}=0.14)$ ve hastalığın bulunduğu periyoda $(\mathrm{p}=0.87)$ göre farklılık yoktu. Egzersiz Değişim Basamağı anketi sonuçlarına göre bireylerin \%29'u(n=38) eğilim öncesi, \%9.9'u $(n=13)$ eğilim, \%17.6's1 $(n=23)$ hazırlık, \%19.1'i $(n=25)$ hareket ve \%24.4'ü $(\mathrm{n}=32)$ devamlılık basamağındaydı. Anket sonuçlarında cinsiyete $(\mathrm{p}=0.40)$ ve hastalığın bulunduğu periyoda göre fark belirlenmedi ( $\mathrm{p}=0.09$ ), (Tablo 3 ).

\begin{tabular}{|c|c|c|c|}
\hline & $\operatorname{Kadın}(n=80)$ & Erkek $(n=51)$ & $p$ \\
\hline UFAA (MET/hafta) & $700.9 \pm 835.4$ & $947.6 \pm 1085.7$ & 0.14 \\
\hline Egzersiz değişsim basamağı & & & 0.40 \\
\hline Eğilim öncesi & $26.3(21)$ & 33.3 (17) & \\
\hline Eğilim & $7.5(6)$ & $13.7(7)$ & \\
\hline Hazırlık & $16.3(13)$ & $19.6(10)$ & \\
\hline Hareket & 22.5 (18) & $13.7(7)$ & \\
\hline Devamlilık & $27.5(22)$ & $19.6(10)$ & \\
\hline $\begin{array}{l}\text { UFAA: Uluslararası Fiziksel Aktiv } \\
\text { p<0.05: değerler \% (n) olarak }\end{array}$ & nketi-kısa form; & ET: metabolik e & eğer;: \\
\hline
\end{tabular}

\section{Katılımcılarda egzersize katılımın önündeki engeller}

Kanser tanılı bireylerde egzersize katılıma engel oluşturduğu bilinen yorgunluk durumu (23) incelendiğinde; \%66.4 $(n=71)$ ile en stk fiziksel ve duygusal yorgunluğun birlikteliği saptandı. Salt fiziksel yorgunluk \%24.3 $(\mathrm{n}=26)$ oranında, duygusal yorgunluk \%9.3 $(\mathrm{n}=10)$ oranında bulundu. Yorgunluğun sıklığı haftada 1-3 gün olarak en çok işaretlenen (\%30.5, $\mathrm{n}=40)$ seçenekti. Yorgunluk durumu ve sıklığ1 açısından, kadın ile erkek arasında ve hastalığın bulunduğu periyoda göre fark yoktu (sırasıyla $\mathrm{p}=0.22, \mathrm{p}=0.78 ; \mathrm{p}=0.82$, $\mathrm{p}=0.89$ ). 
Bireylerin düzenli fiziksel aktivite yapmalarını engelleyen etkenler incelendiğinde; enerji eksikliği (\%32.1), fiziksel (ağrı, bulantı, kusma vb.) belirtiler (\%15.3), fiziksel aktivite yapmayı özendirecek ortam eksikliği (\%8.4) ve fiziksel aktivite hakkında bilgi sahibi olmama (\%5.3) başlıkları öne çıktı. Fiziksel aktivite yapmanın önündeki engeller cinsiyete ve hastalığın bulunduğu periyoda göre farklılık göstermedi (s1rasiyla $\mathrm{p}=0.66$ ve $\mathrm{p}=0.89$ ).

\section{Katılımcılann egzersize yönelik talepleri}

Katılımcıların \%40.5'i ( $\mathrm{n}=53)$ tedaviye başlamadan önce ya da tedavisi sırasında fiziksel aktivite/egzersiz ile ilgili bilgilendirildiğini beyan etti. Egzersiz konusunda bilgi alan kişilerin \%79.6'i ( $\mathrm{n}=43)$ hekim, \%5.4'ü $(\mathrm{n}=3)$ aile/arkadaş çevresi, \%3.7'si $(\mathrm{n}=2)$ hemşire ve \%3.7'si $(\mathrm{n}=2)$ fizyoterapist tarafından bilgilendirilmişti (Şekil 1). Bilgilendirme konusunda cinsiyete ve hastalığın bulunduğu periyoda göre fark yoktu (sirasiyla $\mathrm{p}=0.52, \mathrm{p}=0.48$ ).

\begin{tabular}{|r|c|}
\hline & 1.9 \\
& 1.9 \\
Hekim \& Fizyoterapist & 1.9 \\
& 1.9 \\
Fizyoterapist & 3.7 \\
Hemşire & 3.7 \\
Aile/ Arkadaş Çevresi & 5.4 \\
Hekim &
\end{tabular}

Şekil 1. Egzersiz konusunda bilgilenme kaynağı

'Fiziksel aktivite/egzersiz ile ilgili bilgi almak ister misiniz?" sorusuna \%67.9 ( $\mathrm{n}=89$ ) oranında "evet" yanıtı verildi. Bilgi alma isteği, kadınlar ile erkekler arasında ve hastalık periyoduna göre fark göstermedi (sırasıyla $\mathrm{p}=0.53$, $\mathrm{p}=0.09$ ). Katılımcılar, bilgi kaynağ 1 olarak \%46.7 hekimi (hekimler arasında \%66.2 ile en sık onkoloji uzmanını), $\% 22.2$ fizyoterapisti ve \%11.1 hekim ile fizyoterapist birlikteliğini talep etmekteydi (Şekil 2).

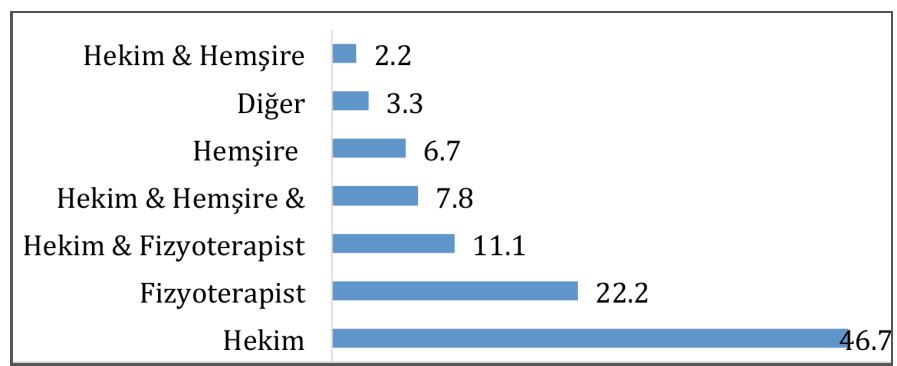

Şekil 2. Egzersiz konusunda bilgilenmek istenilen kaynak

Egzersiz programı hakkındaki bilgi; \%55.6 $(\mathrm{n}=55)$ yüz yüze, $\% 7.1(\mathrm{n}=7)$ telefonla, $\% 6.1(\mathrm{n}=6)$ yüz yüze ve eğitim semineriyle, \%6.1 $(\mathrm{n}=6)$ yüz yüze ve egzersiz broşürü birlikteliğiyle alınmak isteniyordu. Egzersiz programı hakkında bilgilen- dirme zamanı; \%40.8 $(\mathrm{n}=40)$ tedaviye başlamadan önce, \%34.7 $(\mathrm{n}=34)$ tedavi sırasında ve \%12.2 $(\mathrm{n}=12)$ tedavi bitimi sonrası olarak seçildi. Kadınlar bilgilendirme zamanı olarak tedavi bitiminden 3-6 ay sonrayı erkeklere kıyasla daha fazla tercih ediyordu ( $\mathrm{p}=0.01)$. Hastalığın bulunduğu periyoda göre egzersiz programı hakkında bilgilendirme zamanı tercihi fark oluşturmadi $(\mathrm{p}=0.07)$.

Katılımcılar egzersiz programını \%35.9 ( $\mathrm{n}=37$ ) evde, \%35.0 $(\mathrm{n}=36)$ açık alanda veya doğada ve \%11.7 $(\mathrm{n}=12)$ hastanede uygulamak istediklerini bildirdi. Katılımcıların \%31.7'si $(n=32)$ egzersiz sirasinda aile bireyleriyle \%30.7'si $(n=31)$ benzer hastalığa sahip kişilerle bir arada olmak istediklerini bildirirken, \%23.8'i ( $\mathrm{n}=24)$ yalnız egzersiz yapmak istemekteydi. Erkeklerin egzersizi aile bireyleri ile birlikte yapma isteği (\%51.0), kadınlara (\%20.0) göre daha yüksek bulundu ( $\mathrm{p}=0.02)$. Hastalığın bulunduğu periyoda göre hastaların egzersiz programını birlikte sürdürmek istedikleri kişiler fark oluşturmadi ( $\mathrm{p}=0.39)$.

Egzersizi uygulama sıklığ1 olarak \%30.6 ( $\mathrm{n}=30)$ haftanın tüm günlerini, \%28.6 $(\mathrm{n}=28)$ haftada üç günü, \%21.4 $(\mathrm{n}=21)$ hafta sonunu tercih etmekteydi. Egzersiz programının aynı kalmasını isteyenlerin oranı \%39.8 ( $\mathrm{n}=39)$ iken, zaman zaman değiştirilmesini isteyenler \%60.2 $(n=59)$ ile çoğunluktaydı. Egzersiz tipi olarak en sık yürüyüş (\%43.5), yüzme (\%11.5), yoga/pilates (\%9.2) ve bisiklet (\%6.1) tercih edilmekteydi. Egzersiz tipi, sıklığı ve çeşitliliği konusunda cinsiyete ve hastalığın bulunduğu periyoda özgü fark saptanmadı (sirasiyla $\mathrm{p}=0.77, \mathrm{p}=0.22, \mathrm{p}=0.54 ; \mathrm{p}=0.56, \mathrm{p}=0.73$ ve $\mathrm{p}=0.54)$.

Katılımcıların \%35.9'u ( $\mathrm{n=47)}$ önerilen ve anlatılan/gösterilen programı yapamayacağını, $\% 32.81 \mathrm{i}(\mathrm{n}=43)$ yapabileceğini, \%31.3'ü $(n=41)$ belki yapabileceğini düşünüyordu. Kadınların önerilen egzersiz programını yapabilme yönündeki beyanları erkeklerden daha yüksekti $(\mathrm{p}=0.04)$. Hastalığın evresi dikkate alındığında 'Size önerilen ve anlatılan/gösterilen egzersiz programını yapabileceğinizi düşünüyor musunuz?' sorusuna 'evet' yanıtı oranları aktif tedavi döneminde olan bireylerde (\%23.5) takip döneminde olanlardan (\%46.2) daha düşük iken, 'belki' yanıtı oranları (\%32.4) takip döneminde olanlardan (\%26.9) daha yüksekti ( $\mathrm{p}=0.03)$.

Egzersiz programını gözetimli sürdürmek istediğini bildirenlerin oran1 \%68.3'dü ( $\mathrm{n}=69)$. Bu bireyler; \%35.7 ( $\mathrm{n}=25)$ hekim, \%30 $(\mathrm{n}=21)$ fizyoterapist, $\% 10(\mathrm{n}=7)$ hekim ve fizyoterapist birlikte gözetimini talep etmekteydi. Hastalardan; \%30.5'i $(n=40)$ egzersiz programlarının yanı sıra beslenme önerilerine, \%18.3'ü $(n=24)$ destek gruplarına, \%11.5'i $(n=15)$ işe geri dönüş önerilerine ilişkin bilgilendirilmek istiyordu. Bu konuda cinsiyete özgü fark yoktu $(\mathrm{p}=0.49)$. Hastalığın bulunduğu periyod dikkate alındığında yeni tanılı 
bireylerin egzersiz programlarının yanı sıra destek gruplarına ilişkin bilgi almak istedikleri saptand $1(\mathrm{p}=0.04)$.

\section{TARTIŞMA}

Kanser hastalarının fiziksel aktiviteye katılımlarının arttırılması ile tedavi ve sonrasında yan etkilerin azaltılması ve yaşam kalitesinin arttırılması arasında güçlü ilişki saptanmıştır. Fiziksel aktivitenin prognoza güçlü katkılar sağladığı da bilinmektedir (24). Bu bilgiler doğrultusunda ülkemizde kanser hastalarının fiziksel aktivite tutum ve taleplerini değerlendirmek için yaptığımız çalışmada katılımcıların \%26.7'sinin geçmişte düzenli fiziksel aktivite katılımı gösterdikleri ve bu oranın erkeklerde anlamlı şekilde yüksek olduğu saptandı. Katılımcılar UFAA fiziksel aktivite değerlendirmesine göre aktif birey grubunda yer aldılar.

Egzersize engel durumları araştıran çalışmaları inceleyen Clifford ve ark.nın derlemelerinde, egzersizin önündeki temel engeller tedaviye bağlı yan etkiler, zaman eksikliği ve yorgunluk olarak belirlenmiştir (19). Romero ve ark.na göre hastaların fiziksel olarak aktif olmasının önündeki en önemli engeller yorgunluk, ağrı, motivasyon zorluğu ve disiplinli kalmada güçlüktür (23). Höh ve ark., bu engelleri irade eksikliği, zaman eksikliği veya çok meşgul olma, zayıflık, öz disiplinsizlik ve egzersizi öncelik haline getirmeme olarak sıralamışlardır (25). Benzer şekilde; çalışmamızda fiziksel aktivite yapmayı engelleyen etkenler; enerji eksikliği, ağrı, bulantı, kusma gibi fiziksel belirtiler, fiziksel aktivite yapmayı özendirecek ortam eksikliği ve fiziksel aktivite hakkında bilgi sahibi olmama olarak belirlendi. Kanser hastalarına egzersiz yapabilecekleri ortamlar hazırlayarak ve egzersizin sağlıklarına etkileri ve yapabilecekleri egzersizlere ilişkin bilgi düzeylerini arttırmaya yönelik çalışmalar yaparak hastaların fiziksel aktiviteye katılımlarının arttırılabileceği söylenebilir.

Yorgunluk, kanser tedavisinin en sık bildirilen yan etkilerinden biridir ve sıkl1kla egzersiz yapmaya engel olan bir durumdur (26). Öte yandan, kişilerin egzersize katılımının arttırılması ile kanser ve tedavisine ilişkin gelişen yorgunlukta azalma sağlanabileceği bildirilmiştir (27). Araştırmamıza katılanlarda, en sı fiziksel ve duygusal yorgunluğun birlikte görüldüğü saptandı. Bu durum yorgunluğun salt fiziksel kökenli olmadığını, hastalığın psişik yönü dikkate alınarak egzersizin duygudurum üzerinde pozitif etkide bulunabileceğini düşündürmektedir.

Blaney ve ark. hastaların egzersize katılımının önünde yorgunluk, kuvvetsizlik, tedaviye bağlı yan etkilerin yanı sıra yapabilecekleri egzersizler hakkında bilgi sahibi olmamalarının da engel oluşturduğunu belirtmişlerdir (28). Fernandez ve ark. kanser hastalarının \%66'sının fiziksel aktivite hakkında bilgilendirilmediklerini saptamışlardır (29). çalışmamızda hastaların \%40.5'inin tedaviye başlamadan ya da tedavi sırasında bilgilendirildiği ve egzersiz bilgisinin \%76.9 oranındahekim tarafından sağlandığı belirlenmiştir. Hastalarımızın 'egzersizle ilgili bilgi almak ister misiniz?' sorusuna \%67.9 oranında 'evet' yanıtı vermiş olmaları ve fizyoterapist ile hemşirelerden bilgi almak isteyenlerin de bulunması, kanser hastalarının tedavi ekibinde yer alan yardımcı sağlık personelinin de egzersiz bilgilendirmesi sürecine aktif katılımlarının beklendiğinin göstergesidir.

Bluethmann ve ark.na göre egzersiz davranışlarında en büyük değişiklik, yüz yüze danışmanlık hizmeti verilmesi ve egzersiz hiz- metlerinin denetimi ile ortaya çıkmaktadır (30). çalışmamızda egzersiz programını gözetimli olarak sürdürmek istediğini bildirenlerin oranı \%68.3 idi. Egzersiz danışmanlığı hizmetlerine erişimin hastanelerde sinırlı ölçüde mevcut olduğu bildirilmiş (31), meme kanserli gruplarda egzersiz etkisinin incelendiği makalelerin meta-analizinde, daha az maliyetli ve uygulanabilir bir alternatif olarak telefon veya e-posta danışmanlık hizmetlerinin etkisi üzerinde durulmuştur (30). Öte yandan, egzersizin sosyal yararı göz önüne alındığında, denetimli grup egzersizlerinin kanser hastalarında sağlıklı egzersiz alışkanlıklarını kolaylaştırabileceği öne sürülmüştür (19). Bu çalışmalardan yola çıkarak, kanser hastalarına yönelik egzersiz hizmetlerinin yeterli olmadığı ve hastalara sağladığı yararların kanıtlanmış olmasına rağmen göz ardı edildiği belirtilebilir. Hastaların gözetimli egzersiz programı istemleri doğrultusunda fizibilite çalışmaları yapılması gerektiğini düşünmekteyiz. Ayrıca bu gözetimin hekim, fizyoterapist veya birlikteliklerinden talep edilmiş olması nedeniyle, egzersiz programlarının oluşturulması ve izlenmesinde görevli doktor ve fizyoterapistlerin katılımlarının tedavide yarar sağlayabileceğini söyleyebiliriz.

Motivasyon, egzersiz programlarına katılımda sürekliliği sağlayabilmek için kilit bir tetikleyicidir. Berkman ve ark.na göre; kanser hastalarının uzun vadede daha fazla fiziksel aktiviteye katılımları için en etkili stratejiler arasında motive edici konuşma, koçluk ve sosyo-bilişsel öğrenme teorisine göre öğrenme bulunmaktadır (32). Ungar ve ark. bilişsel faktörlerin yanı sıra fiziksel aktiviteden zevk alma gibi duygusal faktörlerin kanser hastalarının fiziksel aktivite düzeyi üzerinde olumlu etkileri olabileceğini belirtmişlerdir (33). Stonerock ve ark.na göre motivasyonel görüşme, zaman yönetimi gibi yaşam tarzına ilişkin engellerin aşılmasında rol oynayabilmekte ve egzersiz uyumunu arttırabilmektedir (34). Felser ve ark. egzersiz motivasyonunu tanımlamak için transteoretik modele uygun geliştirilmiş beş davranış değişim basamağına dayalı kesitsel çalışmalarında, egzersiz deneyimi olanların daha yüksek motivasyon gösterdiğini saptamışlardır. $\mathrm{Bu}$ durum, egzersizin olumlu etkileri hakkındaki bilginin yanı sıra deneyimin önemini de ortaya çıkarmaktadır (35). çalışmamıza katılanların önemli bir kısmının egzersiz programını yapamayacağını veya egzersiz konusunda kararsız olduğunu belirtmesi ve geçmişte düzenli fiziksel aktiviteye/egzersize katılım oranının düşük saptanması, motivasyon açısından destek sağlanması gerektiğini düşündürmektedir.

Felser ve ark. hastaların \%59'unun egzersiz grubuna katılmayı düşündüklerini saptamışlar; hastalık öncesi fiziksel aktiviteye katılmış olanların sağlıklı birey egzersiz gruplarını tercih ederken, bu konuda deneyimsiz hastaların ise özel kanser egzersiz gruplarını tercih ettiklerini belirlemişlerdir (35). çalışmamızda katılımcıların \%31.7'si aile bireyleriyle, \%30.7'si ise benzer hastalığı olanlarla egzersiz yapmayı tercih etmektedir.

Clifford ve ark. katılımcıların egzersize ilişkin önerileri yüz yüze ortamda almayı istediklerini, egzersiz tercihlerine bakıldığında ise en çok tedaviyi tamamladıktan hemen sonra veya 3-6 ay sonra başlayan orta yoğunlukta yürüyüş egzersizini tercih ettiklerini belirtmişlerdir (19). çalışmamızda da benzer şekilde, bilgi almak için yüz yüze ortam tercih edilmiş; bilgilendirme zamanı olarak katılımcıların büyük çoğunluğu tedaviye başlamadan önce ve tedavi dönemini, \%12.2'si tedavi bitiminden hemen sonrasını tercih etmiştir. Tedavi bitiminden 3-6 ay sonra bilgilendirme isteği ise erkeklere kıyasla kadınlarda öne çıkmaktadır. 
Katılımcıların egzersiz davranıșlarına bakıldığında egzersiz değişim basamağı anketine göre bireylerin \%29'luk bir oranla en çok eğilim öncesi aşamasında olmaları, egzersize teşvik için müdahale gerekliliğini düşündürmektedir. Geçmişte fiziksel aktiviteye katılım oranı \%26.7 olup egzersiz değişim basamakları değerlendirdiğinde egzersize devamlılık oranı ise \%24.4 olarak bulunmuştur. Buentzel ve ark. 155 hasta ile yaptıkları çalışmada; kanser tanısı öncesinde bireylerin $\% 71$ 'inin aktif olduğunu saptamışlar ve tedavi döneminde oranın $\% 45^{\prime}$ e gerilediğini belirlemişlerdir (36). çalışmamızda hastaların sağlıklıyken fiziksel aktiviteye katılımları da, devamlılık aşamasında egzersizi bırakanların sayısı da daha az bulundu. Buna göre ülkemizde her yaş ve koşulda fiziksel aktivitenin arttırılması ve 'sağlık için hareket et' kavramının yerleștirilmesi gerektiği yorumu yapılabilir.

çeşitli çalışmalarda, kontrendikasyon yoksa kanser hastalarının olabildiğince erken egzersiz programına başlamasının fiziksel ve zihinsel bileşenleri korumada yarar sağladığı, düzenli egzersiz yapma motivasyonunun hastalık öncesi ve tedavi sırasında fiziksel aktivite deneyimine bağlı olduğu ve egzersiz konusunda deneyimsiz hastalara özel kanser egzersiz grupları oluşturulmasının yarar sağlayabileceği belirtilmiştir $(25,35)$.

çalışmanın kesitsel nitelik taşıması, fiziksel aktivite düzeyi saptanırken son hafta verilerinin kullanılmış olması ve düzenli ilaç kullanım oranlarının beklenenden daha düşük oranda bulunması k1sıtlılıkları oluşturmaktadır. Ayrıca hastaların \%32.1'inin bilinen ek hastalığı bulunup, bu durumun hastaların fiziksel aktiviteye katılımlarını veya davranış basamaklarını etkileyip etkilemediğinin bilinmemesi bir diğer kısıtlılıktır.

Sonuç olarak; çalışmamızda kanser hastalarının egzersiz davranışları, egzersiz yapılmasının önündeki engeller ve fiziksel aktiviteye katılımın artması için taleplerin neler olduğunun saptanması hedeflenmiştir. Hastaların istekleri doğrultusunda, gerekli bilgilendirmelerin yapılarak fiziksel aktiviteye katılımın arttırılması için desteklenmeleri gerektiği çıkarımı yapılmıştır. Kanser hastalarının egzersiz yapmalarına engel durumların gözden geçirilerek değiştirilebilir faktörlere müdahale edilmesi ve fiziksel aktiviteye yönelik taleplerinin dikkate alınarak egzersizin tedavi sürecinin bir parçası haline getirilmesi hastaların sağlığına katkıda bulunacaktır. Hastaların tedavilerinde yer alan aile bireyleri, doktorlar, fizyoterapistler ve destek gruplarının sürece dahil edilerek bilgi ve yardım sağlamada bütüncül bir yaklaşım sergilenmesi önemlidir. Ülkemizde bireylerin gereksinim ve talepleri göz önüne alınarak yapılandırılmış, sağlık ekibi tarafından onaylanmış, bireyselleştirilmiş ve değişikliklerle hasta motivasyonuna katkı sağlayacak egzersiz programlarının oluşturulması hastaların fiziksel aktiviteye katılım ve devam ettirme oranlarını arttıracaktır.

\section{Acknowledgments / Teşekkür}

Bu çalışmada bizden desteğini esirgemeyen başta Cemaliye Bardakçı, Nurcan Anakurt ve Halil Tanrıverdi olmak üzere Isparta Kansev Derneği çalışanları ile Nihal Akar ve Sibel Akar başta olmak üzere Sakarya Kanserder Derneği çalışanlarına katkılarından dolayı teşekkür ederiz.

\section{Conflict of Interest / Çıkar Çatışması}

The authors declared no conflicts of interest with respect to authorship and/or publication of the article.

Financial Disclosure / Finansal Destek
The authors received no financial support for the research and/or publication of this article.

\section{KAYNAKLAR}

1. Bayrak E. Bulaşıcı olmayan hastalıklarda kişiye özgü risk değerlendirmeleri ve kanser taramaları. Sağlık ve Toplum.2020;30(2):29-45.

2. Torre LA, Siegel RL, Ward EM, Jemal A. Global cancer incidence and mortality rates and trends an update. Cancer Epidemiol Biomarkers Prev. 2016;25(1):16-27.

3. Ferlay J, Soerjomataram I, Dikshit R, Eser S, Mathers C, Rebelo M, et al. Cancer incidence and mortality worldwide: sources, methods and major patterns in GLOBOCAN 2012. Int J Cancer. 2015;136(5):E359-86.

4. Hashim D, Boffetta P, La Vecchia C, Rota M, Bertuccio P, Malvezzi M, et al. The global decrease in cancer mortality: trends and disparities. Ann Oncol. 2016;27(5):926-33.

5. Rock CL, Doyle C, Demark-Wahnefried W, Meyerhardt J, Courneya KS, Schwartz AL, et al. Nutrition and physical activity guidelines for cancer survivors. CA Cancer J Clin. 2012:62(4):243-74.

6. Buffart LM, Galvão DA, Brug J, Chinapaw MJM, Newton RU. Evidence-based physical activity guidelines for cancer survivors: current guidelines, knowledge gaps and future research directions. Cancer Treat Rev. 2014;40(2):327-40.

7. Midtgaard J, Hammer NM, Andersen C, Larsen A, Bruun DM, Jarden M. Cancer survivors' experience of exercise-based cancer rehabilitation - a meta-synthesis of qualitative research. Acta Oncol. 2015;54(5):609-17.

8. Padilha CS, Marinello PC, Galvão DA, Newton RU, Borges FH, Frajacomo F, et al. Evaluation of resistance training to improve muscular strength and body composition in cancer patients undergoing neoadjuvant and adjuvant therapy: a meta-analysis. J Cancer Surviv. 2017;11(3):339-49.

9. Borch KB, Braaten T, Lund E, Weiderpass E. Physical activity before and after breast cancer diagnosis and survival - the Norwegian women and cancer cohort study. BMC Cancer. 2015; 15:967. doi: 10.1186/s12885-015-1971-9.

10. Wang A, Qin FF, Hedlin H, Desai M, Chlebowski R, Gomez S, et al. Physical activity and sedentary behavior in relation to lung cancer incidence and mortality in older women: The Women's Health Initiative. Int J Cancer. 2016;139(10):2178-92.

11. Tarasenko Y, Chen C, Schoenberg N. Self-reported physical activity levels of older cancer survivors: results from the 2014 National Health Interview Survey. J Am Geriatr Soc. 2017;65(2):e39-44.

12. Demark-Wahnefried W, Rogers LQ, Alfano CM, Thomson CA, Courneya KS, Meyerhardt JA, et al. Practical clinical interventions for diet, physical activity, and weight control in cancer survivors. CA Cancer J Clin. 2015;65(3):167-89.

13. Moore SC, Lee IM, Weiderpass E, Campbell PT, Sampson JN, Kitahara CM, et al. Association of leisure-time physical activity with risk of 26 types of cancer in 1.44 million adults. JAMA Intern Med. 2016;176(6):816-25.

14. Cheville AL, Mustian K, Winters-Stone K, Zucker DS, Gamble GL, Alfano CM. Cancer rehabilitation: an overview of current need, delivery models, and levels of care. Phys Med Rehabil Clin N Am. 2017;28(1):1-17.

15. MacAuley D, Bauman A, Frémont P. Exercise: not a miracle cure, just good medicine. $\mathrm{Br} J$ Sports Med. 2016;50(18):1107-8.

16. Smaradottir A, Smith AL, Borgert AJ, Oettel KR. Are we on the same page? Patient and provider perceptions about exercise in cancer care: a focus group study. J Natl Compr Cancer Netw. 2017;15(5):588-94.

17. Buffart LM, Newton RU, Chinapaw MJ, Taaffe DR, Spry NA, Denham JW, et al. The effect, moderators, and mediators of resistance and aerobic exercise on health-related quality of life in older long-term survivors of prostate cancer. Cancer. 2015;121(16):2821-30.

18. Kalter J, Buffart LM, Korstjens I, van Weert E, Brug J, Verdonck-de Leeuw IM, et al. Moderators of the effects of group-based physical exercise on cancer survivors' quality of life. Support Care Cancer. 2015;23(9):2623-31.

19. Clifford BK, Mizrahi D, Sandler CX, Barry BK, Simar D, Wakefield CE, et al. Barriers and facilitators of exercise experienced by cancer survivors: a mixed methods systematic review. Support Care Cancer. 2018;26(3):685-700.

20. Saglam M, Arikan H, Savci S, Inal-Ince D, Bosnak-Guclu M, Karabulut E, et al. International physical activity questionnaire: Reliability and validity of the Turkish version. Percept Mot Skills. 2010;111(1):278-84.

21. Cengiz C, Aş̧̧ F, İnce ML. Egzersiz davranışı değişim basamakları anketi. Geçerlik ve güvenirlik çalışması. Türkiye Klinikleri Spor Bil Derg. 2010;2(1):32-7.

22. Elbasan B, Düzgün İ. Fiziksel aktivite skalaları-kanıta dayalı fiziksel aktivite. Türkiye Klinikleri J Physiother Rehabil-Special Topics. 2016;2(1):36-9.

23. Romero SAD, Brown JC, Bauml JM, Hay JL, Li QS, Cohen RB, et al. Barriers to physical activity: a study of academic and community cancer survivors with pain. J Cancer Surviv. 2018;12(6):744-52. 
24. Hvid T, Lindegaard B, Winding K, Iversen P, Brasso K, Solomon TPJ. Effect of a 2-year homebased endurance training intervention on physiological function and PSA doubling time in prostate cancer patients. Cancer Causes Control. 2016;27(2):165-74.

25. Höh JC, Schmidt T, Hübner J. Physical activity among cancer survivors-what is their perception and experience? Support Care Cancer. 2018;26(5):1471-8.

26. Sandler CX, Goldstein D, Horsfield S, Bennett BK, Friedlander M, Bastick PA, et al. Randomized evaluation of cognitive-behavioral therapy and graded exercise therapy for post-cancer fatigue. J Pain Symptom Manage. 2017;54(1):74-84.

27. Canário ACG, Cabral PUL, de Paiva LC, Florencio GLD, Spyrides MH, da Silveria Gonçalves AK. Physical activity, fatigue and quality of life in breast cancer patients. Rev Assoc Méd Bras (1992). 2016;62(1):38-44

28. Blaney JM, Lowe-Strong A, Rankin-Watt J, Campbell A, Gracey JH. Cancer survivors' exercise barriers, facilitators and preferences in the context of fatigue, quality of life and physical activity participation: a questionnaire-survey. Psychooncology. 2013;22(1):186-94.

29. Fernandez S, Franklin J, Amlani N, DeMilleVille C, Lawson D, Smith J. Physical activity and cancer: A cross-sectional study on the barriers and facilitators to exercise during cancer treatment. Can Oncol Nurs J. 2015:25(1):37-48.

30. Bluethmann SM, Vernon SW, Gabriel KP, Murphy CC, Bartholomew LK. Taking the next step: a systematic review and meta-analysis of physical activity and behavior change interventions in recent post-treatment breast cancer survivors. Breast Cancer Res Treat. 2015;149(2):331-42.
31. Smith L, Croker H, Fisher A, Williams K, Wardle J, Beeken RJ. Cancer survivors' attitudes towards and knowledge of physical activity, sources of information, and barriers and facilitators of engagement: a qualitative study. Eur J Cancer Care (Engl).2017;26(4). doi: 10.1111/ecc.12641.

32. Berkman AM, Gilchrist SC. Behavioral change strategies to improve physical activity after cancer treatment. Rehabil Oncol. 2018;36(3):152-60.

33. Ungar N, Wiskemann J, Sieverding M. Physical activity enjoyment and self-efficacy as predictors of cancer patients' physical activity level. Front Psychol. 2016;7:898. doi: 10.3389/fpsyg.2016.00898.

34. Stonerock GL, Blumenthal JA. Role of counseling to promote adherence in healthy lifestyle medicine: strategies to improve exercise adherence and enhance physical activity. Prog Cardiovasc Dis. 2017;59(5):455-62.

35. Felser S, Behrens M, Lampe H, Henze L, Grosse-Thie C, Murua Escobar H, et al. Motivation and preferences of cancer patients to perform physical training. Eur J Cancer Care (Engl). 2020; 29(4):e13246. doi: 10.1111/ecc.13246.

36. Büntzel J, Kusterer I, Rudolph Y, Kubin T, Micke 0, Hübner J. Cancer patients' knowledge and acceptance of physical activities for rehabilitation. In vivo. 2017:31(6):1187-92. 